\title{
Direito ou benefício? Política de assistência estudantil e seus efeitos subjetivos aos universitários
}

Jardel Pelissari Machado. Universidade Federal do Paraná.

Miriam Aparecida Graciano de Souza Pan. Universidade Federal do Paraná.

\section{Resumo}

Analisou-se os efeitos subjetivos da Política Nacional de Assistência Estudantil (PNAES) aos estudantes de uma universidade federal brasileira, a partir de uma leitura bakhtiniana. Os enunciados de estudantes participantes de dez entrevistas e dois grupos focais foram analisados dialogicamente com a legislação que regulamenta a política e as resoluções que a implementam na Universidade Federal do Paraná. O sentimento de vergonha faz-se ouvir nos discursos dos estudantes, assim como, para a constituição de direitos, as tensões entre sentidos de dependência, trabalho, estudo e ócio. Discute-se sobre como esses sentidos operam pela gestão e controle da alteridade, fixando identidades e sobre seus efeitos ao cotidiano dos estudantes, assim como de que forma estes respondem, tensionam e reconstroem esses sentidos, transformando suas possibilidades de ser, agir e de se reconhecerem na universidade, deslocando o eixo de reflexão de um nível de responsabilização e culpabilização individual para a arena social e política.

Palavras-chave: estudantes universitários; subjetividade, políticas públicas; direito; assistência.

\begin{abstract}
Right or benefit? Student assistance policy and its subjective effects to university students. Analyzes the subjetive effects of the National Policy of Student Assistance to university students of a federal Brazilian university throug a bakhtinian reading. The speech of students participants from ten interviews and two focus groups were analyzed dialogically with the legislation thats regulates the policy and resolutions that implements it at the Federal University of Paraná. The sense of shame is heard in the speeches of students, as well as, to the estalishment of rights, tensions between the meanings of dependence, work, study and leisure. We discuss how these meanings operates on the management and control of otherness, establishing identities and about their effects on everyday students, as well as how they respond, tensionning and reconstruct these meanings, making your chances of being, acting and if recognize the university, shifting the axis of reflection of a level of accountability and individual blame for the social and political arena.
\end{abstract}

Keywords: university sudents; subjetcivity; public policy; right; assistance.

\section{Resumen}

Derecho o beneficio? La política de asistencia a los estudiantes y sus efectos subjetivos a los estudiantes universitarios. Analizados los efectos subjetivos de la Política Nacional de Asistencia de Estudiantes a los estudiantes de una universidad federal de Brasil a través de una lectura bajtiniana. Los enunciados de estudiantes fueron analizados de manera dialógica con la legislación que regula la política y las resoluciones que la implementan en la Universidad Federal de Paraná. El sentimiento de vergüenza se escucha en los discursos de los estudiantes, así como, para el establecimiento de derechos, las tensiones entre los sentidos de dependencia, el trabajo, el estudio y el ocio. Se discute cómo estos sentidos operan la gestión y control de la alteridad, el establecimiento de identidades y cómo la experiencian los estudiantes en su vida diaria, cómo responden, tensionan y reconstruyen estos sentidos, transformando sus posibilidades de ser, de actuar y de reconocerse en la universidad, cambiando el eje de la reflexión de un nivel de responsabilidad y culpabilización individual para la arena social y política.

Palabras clave: estudiantes universitarios; subjetividad; política pública; derecho; asistencia. 
Este estudo analisa os fundamentos do Programa Nacional de Assistência Estudantil (PNAES), criado pelo governo federal brasileiro em 2007, e seus efeitos na subjetividade dos estudantes de uma universidade federal. A assistência estudantil no Ensino Superior tornou-se temática relevante na agenda do governo nos últimos anos, impulsionada pela assunção de compromissos em nome da democratização da educação e garantia de direitos, marcadamente emergentes no fim da década de 1980 (Machado \& Pan, 2012). Na educação superior pública brasileira essas discussões produziram uma sequência de ações com vistas a atingir esses objetivos. Dentre elas o Programa de Apoio a Planos de Reestruturação e Expansão das Universidades Federais (REUNI), as políticas de reservas de vagas a grupos sub-representados na universidade (conhecidas como cotas) e o Plano Nacional de Assistência Estudantil (PNAES) ${ }^{1}$. Diferente das primeiras, que tinham como foco a ampliação de vagas e o acesso dos estudantes às universidades, o PNAES tem por objetivo criar condições para a permanência de estudantes nas Instituições Federais de Ensino Superior (IFES), combatendo o abandono da instituição.

As atuais discussões sobre a assistência estudantil no Brasil emergem a partir do debate entre o Fórum Nacional de Pró-Reitores de Assuntos Comunitários e Estudantis (FONAPRACE) e o Ministério da Educação (MEC) no início dos anos 2000. Segundo dados do FONAPRACE (2001), corroborados por estudo de Pacheco e Ristoff (2004), grande parte dos estudantes que abandonavam o ensino superior tinham baixa renda, o que os obrigava, muitas vezes, a trocar os estudos por trabalho. Decorrente dessas discussões, o PNAES surge como proposta para sanar essa problemática, instituído no fim de $2007^{2}$. Essa temática tem produzido discussões sobre diversos aspectos envolvidos nesse campo, como a moradia estudantil (Garrido, 2015), o mercado de trabalho para bolsistas egressos (Vargas, 2011), a importância dessas ações para o combate à evasão (Bardagi \& Hutz, 2009), assim como seus efeitos no cotidiano dos estudantes (Machado \& Pan, 2013, 2014). Ao mesmo tempo em que promovem condição para a conclusão dos estudos, essas ações produzem sentidos que tencionam o cotidiano dos estudantes, com questões como: estudar em uma universidade pública de alto prestígio e de grande concorrência é um direito ou um privilégio de poucos? Quem conquista uma vaga em uma IFES e recebe auxílio para custear suas despesas, é um beneficiado ou cidadão com direitos garantidos? Quais os sentidos de ser bolsista (PNAES) em uma instituição federal?
Tais questões atravessam essas instituições, não tendo origem nelas mesmas, pois refletem e refratam a ordem social vigente, ocupando lugares centrais nas tensas negociações de sentido sobre os processos de exclusão/inclusão (Sawaia, 2006) nas universidades, assim como em processos que definem identidades, modos de ser e agir aos estudantes participantes dessas políticas (Machado \& Pan, 2014).

A história das políticas de assistência, segundo Monnerat, Senna, Schottz, Magalhães, e Burlandy (2007) acompanha o desenvolvimento do capitalismo desde os séculos XVII e XVIII. Suas ações sustentavam-se em concepções moralistas ou culturalistas da pobreza, como descreve Silva (2010), atribuindo suas causas a falhas individuais ou a culturas inferiores, respectivamente. Decorrem delas ações com caráter punitivo ou modelador de condutas, com exigências de contrapartidas ou de condutas a serem seguidas em troca dos valores ou bens. Os questionamentos a essa lógica emergem com a compreensão da pobreza como uma "questão social", termo que passa a ser utilizado para designar o conjunto de desigualdades produzidas pela sociedade capitalista, o que acarreta o compromisso de que todos devem participar na provisão de bem-estar a todos os cidadãos - há, pois, um redimensionamento da noção de direito social (Monnerat et al., 2007). Os programas de transferência de renda, como são chamadas as ações de assistência a partir dessa nova noção, não são compreendidos de um único modo: há grupos que compreendem que proporcionar uma renda universal a todos, de forma incondicional, é fundamental para conferir cidadania aos excluídos (que renda não deve ser consequência de quantidade de trabalho); outro, que a transferência de renda pode alimentar uma cidadania passiva, reforçando o papel do Estado como agente de solidariedade, enfraquecendo os circuitos de responsabilização social por não produzirem inserção social dos excluídos (Diniz, 2007; Monnerat et al., 2007); e, ainda, outro que propõe que as contrapartidas garantiriam o que chamam de cidadania ativa, não apenas garantindo o direito à vida, mas também o direito à vida em sociedade, à participação civil e política. Das contrapartidas emergem os questionamentos: se não estariam condicionando um direito em casos em que os beneficiários, muitas vezes, já estão em situações bastante vulneráveis; ou se representariam uma possibilidade de combinação do assistencial/compensatório com o estrutural (Monnerat et al., 2007, p. 1459). A contrapartida põe a discussão do mérito como quesito para o qual se busca uma resposta. 
O mérito, segundo Gentili (1995), é o que fundamenta o individualismo competitivo, sustentando um ideário que legitima e justifica a divisão hierarquizada das sociedades contemporâneas em grupos dualizados, significados como ganhadores ou perdedores, integrados ou excluídos. Assim, a desigualdade configura-se como pré-condição para que se exerça o princípio do mérito, o qual, em resposta aos discursos neoliberais, como expõe Gentili (1995, p. 234), sustenta a compreensão da possibilidade de mobilidade social, pautada em atributos individuais, mantendo a lógica individualista tal como descrita por Mancebo (2004) e Palangana (2002). Nessa forma de compreensão, o indivíduo é o responsável exclusivo por si, por seus sucessos e fracassos, um empresário de si mesmo (Maia \& Mancebo, 2010). Para Yasbek (2003), essa lógica reforça a compreensão individualista de questões sociais, apagando o reconhecimento da pobreza e da exclusão social como expressões de relações sociais e econômicas.

Sawaia (2006) tensiona e complexifica essas questões ao propor pensar a exclusão/inclusão como uma expressão dialética, não como categorias opostas, pois "são da mesma substância e formam um par indissociável, que se constitui na própria relação" (Sawaia, 2006, p. 108). Assim, propõe pensar a exclusão como um processo complexo que, ocorrendo sob a égide das relações econômicas, não se reduz a ela, sendo mediada também por outras determinações sociais - um processo que não pode ser resumido a estar ou não incluído. Engloba o pensar, o sentir e o agir dos sujeitos envolvidos. Assim, propõe que a exclusão/inclusão seja analisada com base no conceito de sofrimento ético-político, o qual retrata a vivência cotidiana das questões sociais dominantes em cada época, especialmente a dor que surge da situação social de ser tratado como inferior, subalterno, sem valor, apêndice inútil da sociedade. O sofrimento revelaria sentidos da vivência cotidiana da desigualdade social, da negação imposta socialmente às possibilidades da maioria apropriar-se da produção material, cultural e social de sua época, de se movimentar no espaço público e de expressar desejo e afeto (Sawaia, 2006, p. 104-105). A pesquisadora introduz a afetividade e as emoções como forma de conhecer sentidos que os sujeitos dão às suas experiências, comportamentos que adotam em relação a si e aos outros. Uma dimensão para pensar a exclusão/inclusão como processo em constante tensão e constituição, processos que são foco das políticas públicas de assistência.
Pesquisar uma Política Pública (PP) requer ir além de seus aspectos técnicos. Requer compreender que sua complexidade é efeito/produto de concepções e fundamentos, envolvendo sua recepção (no sentido de leitura), sua execução e, especialmente, seus efeitos. Entram em cena, portanto, questões como: quem define quais são as problemáticas a serem solucionadas (Frey, 2000); quais os pressupostos e teorias de sociedade que definem os problemas e soluções (Martins, 2001); há ou não a participação da população-alvo na elaboração dessas problemáticas e soluções (Sposito, 2008; Telles, 1998); as influências de agências financiadoras internacionais e outras instituições (Moraes, 2002); assim como o processo de homogeneização das demandas sociais (Martins, 2001). Desse modo, sustenta-se a compreensão das PP tal qual delineada por Machado e Pan (2013; 2014): são enunciados de sujeitos posicionados estrategicamente nas relações de poder, respondendo a e constituindo determinados contextos, sustentados por/em posicionamentos semântico-axiológicos ${ }^{3}$. Enunciados que são, a uma só vez, produto e produtores de efeitos de sentidos em diferentes esferas da vida, impactando na (re)produção ou (trans)formação de valores a partir dos quais e nos quais os sujeitos enunciam, se posicionam, se subjetivam (Bakhtin, 1997; Bakhtin \& Volochínov, 1990; Faraco, 2003; Geraldi, 2010; Pan, Rossler, Ferrarini, Valore, \& Oliveira, 2011). Assim, as PP são compreendidas a partir do dialogismo bakhtiniano (Bakhtin, 1997; Faraco, 2003), não estando encerradas em seus limites físicos (contidos apenas nos documentos escritos), remetendo a outros enunciados, constitutivos do atual (enquanto resposta ativa). São um elo de uma cadeia responsiva, em sua historicidade discursiva, na "grande temporalidade" (Bakhtin, 1997, p. 414), inserida no diálogo entre vozes sociais (Faraco, 2003), nas divergentes formas de posicionamento dos grupos sociais, na arena discursiva. Nesse mesmo diálogo, esses enunciados inserem no tenso e constante processo intersubjetivo de negociação de sentidos, os reafirmando ou os transformando.

Com base na compreensão de que "a consciência só pode surgir e se afirmar como realidade mediante a encarnação material em signos" (Bakhtin \& Volochínov, 1990 , p. 33), sendo estes "o alimento da consciência individual, a matéria de seu desenvolvimento, e ela reflete sua lógica e suas leis" (p. 35), o sujeito (ou a consciência individual) também é caracterizado pelo dialogismo, constituído como uma arena povoada de vozes sociais sempre em conflito, pois, enquanto sujeito, inserido em 
uma sociedade, em um momento histórico, compõe-se também a partir da tensão constitutiva da linguagem. Recusa-se, assim a qualquer determinismo absoluto, afirmando o sujeito como social e singular - singularização de si e de seu discurso por meio da atualização constante na interação viva com as vozes sociais - sempre há réplica no grande diálogo sem fim (Bakhtin, 1997). O sujeito não é reflexo de uma sociedade exterior nem origem absoluta de seus enunciados, mas posicionado nas tensões das vozes sociais, sendo por elas constituído. Enunciar é posicionar-se na linguagem, pressupondo o constante e tenso diálogo entre vozes sociais que se reflete e refrata na singularidade do sujeito. No mesmo sentido, se depreende da teoria do enunciado do Círculo de Bakhtin a concepção de sujeito que, "sendo um eu-para-si, condição de formação da identidade subjetiva, é também um eu para-o-outro, condição de inserção dessa identidade no plano relacional responsável/responsivo, que Ihe dá sentido." (Sobral, 2005, p. 22). Sujeito que é constituído por e que constitui o outro, acabamento sempre provisório; acontecimento em constante devir, o existir-evento, constitui-se sempre aberto, e não enquanto condicionado por um mundo pré-dado, pronto e acabado (Bakhtin, 2010).

A partir do exposto, considerando a complexidade que envolve o estudo de uma PP, em especial ao concebê-la enquanto texto vivo, na concepção do dialogismo bakhtiniano, e com especial destaque à dimensão de sua leitura e seus efeitos na produção de subjetividade, este estudo tem por objetivo analisar os sentidos do PNAES e seus efeitos aos estudantes inseridos nesse programa.

\section{Do pesquisar}

Realizou-se uma pesquisa qualitativa que se pautou em: um estudo documental do PNAES e de sua implantação da Universidade Federal do Paraná (UFPR); e em entrevistas e grupos focais com estudantes inseridos nessa política.

A pesquisa documental permitiu ampliar a compreensão sobre as IFES, seus processos de democratização e suas transformações - o cenário polifônico (Amorim, 2002). Os documentos foram tomados como consolidadores de opções políticas e ideológicas do Estado brasileiro (Severino, 2008), pois "tratam de comportamentos, modos de agir e não agir, adequados, esperados, proibidos, obrigatórios, punitivos. Abordam o que é válido ou deixa de ser, quem deveria segui-las, em que momentos e espaços" (Spink et al., 2014, p. 217).
$\mathrm{Na}$ análise, teceu-se um diálogo entre os documentos, assim como das vozes que os compõem. A produção dos dados com os estudantes se deu com base em dois métodos: entrevistas (Aragaki, Lima, Pereira, \& Nascimento, 2014); e grupos focais (Flick, 2009; Minayo, 2004). Ambos foram conduzidos com base na filosofia bakhtiniana da linguagem ( Bakhtin, 1997; Bakhtin \& Volochínov, 1990; 2010; Freitas, 2002, 2009; Jobim e Souza \& Albuquerque, 2012; Jobim e Souza \& Castro, 1998).

Os participantes das entrevistas foram convidados a participar do estudo via contato telefônico após seleção de nomes de estudantes inseridos há mais de um ano no PROBEM. Os que compuseram os grupos candidataram-se a participar após convite público feito em reunião de boas-vindas realizada em auditório pela PRAE. Foram realizadas dez entrevistas individuais e dois grupos focais - somando no total de 16 estudantes participantes. Os participantes da pesquisa foram estudantes de ambos os sexos, com idades entre 18 e 32 anos, todos bolsistas permanência (PROBEM) há mais de um ano, nove ingressantes por sistema de cotas, de cursos de todos os setores da UFPR, em sua maioria do Setor de Ciências Humanas.

Para as entrevistas e grupos utilizou-se um roteiro, não fechado, de questões utilizadas como fio condutor. As entrevistas ou grupos eram iniciados solicitando aos participantes que narrassem suas histórias educacionais (ensino fundamental, médio e cursinho; condições econômicas; trabalho; escolha do curso; etc.) até o ensino superior. Após, conduzia-se o diálogo à situação do estudante na universidade (o processo de conseguir a bolsa; que tipo de ajuda a bolsa oferecia; os sentidos de ser bolsista e os efeitos para seu cotidiano acadêmico e para o contexto das relações sociais; sua importância para a continuidade dos estudos). Cada um dos grupos teve três encontros que duraram aproximadamente duas horas cada, o primeiro com quatro participantes e o segundo com dois. Os grupos tiveram um grande número de inscritos que se disponibilizaram a participar, porém a adesão foi pequena. Manteve-se o planejado em função do engajamento e assiduidade dos que participaram. Embora o número menor de participantes, o debate coletivo enriqueceu o processo de produção de dados e possibilitou a triangulação dos mesmos com os dados de entrevistas e estudos documentais. Todas as entrevistas e grupos foram gravados em áudio e transcritos. Nas transcrições os estudantes foram identificados com nomes fictícios e com uma letra antes dos nomes, a qual identifica o método de produção do dado ( $E$, para entrevista; e G, para grupo focal 1 ou 2). 
Os trechos selecionados a partir do material produzido com os estudantes teve como foco questões que foram com eles problematizadas, tais como: como compreendem os auxílios que recebem? Que lugares-sentidos são constituídos pela política aos estudantes? Que acabamentos Ihes são dados? De que modo respondem e reconstroem esses acabamentos e imagens? A seleção pautou-se na compreensão de que, como descreve Amorim (2002), não há possibilidade de restituição de sentidos que emergem no contexto de enunciação e de que o texto de pesquisa constitui-se um novo enunciado, em um novo (com)texto. A análise se deu com base na filosofia do Círculo de Bakhtin (Bakhtin \& Volochínov, 1990; Amorim, 2004; Faraco, 2003), na compreensão da palavra como signo ideológico, ou seja, que é na e pela palavra que é possível apreender movimentações de transformação de significações, negociações de sentidos, que produzem como efeito (e que são constituídos por) cenários de experiências cotidianas de determinada sociedade, num determinado tempo.

Os diálogos foram analisados como respostas tanto ao contexto imediato e ao pesquisador, quanto aos documentos e contextos de onde se fazem ouvir as vozes que constituem a universidade e as políticas nessa instituição. Do mesmo modo, se buscou evidenciar os modos como os estudantes desconstroem e reconstroem sentidos sobre seus cotidianos na universidade. Tecendo um diálogo das falas dos estudantes com as vozes sociais que constituem os documentos e contextos, buscou-se compreender os modos como os estudantes respondem, se posicionam, às/frente às tensões dos sentidos da bolsa e de ser bolsista.

\section{Textos e (com)textos do PNAES}

O PNAES (Decreto nำ 7.243, 19 de julho de 2010), é composto por ações com foco em diversas esferas: moradia, alimentação, transporte, saúde, inclusão digital, cultura, esporte, entre outros. Cada IFES tem a responsabilidade de criar e gerenciar suas formas de combater a evasão dos estudantes; tem autonomia para criar programas, bolsas e outras formas de auxílios, assim como os regimentos que regulamentam cada um desses auxílios.

Na UFPR a discussão sobre as políticas de permanência produziu a criação da Pró-Reitoria de Assuntos Estudantis, no início do ano de $2008^{4}$, desmembrada da Pró-Reitoria de Recursos Humanos e Assuntos Estudantis (PRHAE), da qual também surge a Pró-Reitoria de Gestão de Pessoas (PROGEPE). Como atribuição da PRAE, dentre outras, está a implantação e manutenção do PNAES. Uma das formas pelas quais é implantado é o Programa de Benefícios Econômicos para Manutenção (PROBEM). De acordo com a Resolução 31/09 do COUN-UFPR, esse programa é voltado "aos estudantes da Universidade Federal do Paraná (UFPR) com fragilidade econômica com o objetivo de garantir sua permanência na formação na UFPR" (Resolução № 31/09 - COPLAD). O PROBEM disponibiliza bolsas Moradia (auxílio para pagamento de aluguéis), Alimentação (isenção dos valores cobrados nos Restaurantes Universitários) e Permanência (valor para gastos com a vida acadêmica).

Segundo o artigo 6ํำ da resolução, "A concessão dos benefícios do PROBEM terá por base um indicador de fragilidade econômica, do estudante e sua família, mediante análise do cadastro, entrevista e, se necessário, visita domiciliar". Para manter-se no programa, o artigo $7^{0}$ define requisitos a serem cumpridos: matricular-se nas disciplinas correspondentes a etapa curricular ou ser acompanhado por equipe da PRAE; obter aprovação em no mínimo 75\% das disciplinas cursadas; não reprovar na mesma disciplina e não cancelar matrícula de disciplinas em duas etapas curriculares consecutivas. A resolução institui, no art. 11, que a PRAE "disponibilizará normas operacionais complementares, os formulários e os termos de compromisso". Dentre essas normas complementares estão: os critérios de avaliação de "fragilidade econômica"; e o desempenho de 12 horas semanais de atividades formativas em algum órgão da universidade (desde a entrada em vigor do PROBEM até o ano de 2013). As atividades formativas seguiam um plano elaborado por professor ou servidor técnico e deveriam contemplar a área de formação do estudante. Esses planos eram avaliados por pedagogas da UFPR, as quais também alocavam os estudantes, conforme seus cursos e solicitações dos projetos, para atividades a serem desempenhadas. A norma complementar que instituía as 12 horas semanais de atividades formativas seguiu modelo da bolsa-trabalho, extinta assim que iniciam as políticas de permanência na UFPR, e que era vinculada à PRAHE. Na bolsa-trabalho o estudante desempenhava atividades administrativas em algum setor da universidade, sob supervisão da PRHAE. Assim, até 2013, os estudantes que tinham bolsa permanência deveriam, além dos critérios acadêmicos, desempenhar atividades em algum espaço da UFPR. Em meio a esse cenário foi que buscamos um diálogo com os estudantes bolsistas da UFPR. 


\section{Frágeis ou Durões?}

As entrevistas e os grupos focais tiveram início com a apresentação dos estudantes e com o relato de suas experiências educacionais, seguidos pela discussão sobre temas que colocavam em evidência situações cotidianas que configuravam os lugares/sentidos (positivos ou negativos) do ser estudante bolsista e os sentimentos que suscitavam: alegria, tristeza, sofrimento, tensão, etc. A primeira pista que motivou o questionamento sobre essas questões foi o fato de as unidades da UFPR responsáveis pelos processos de cotas no vestibular não divulgarem os nomes dos estudantes ingressantes por essa política. A omissão era justificada como forma de não expor os estudantes a possíveis situações de discriminação. Frente a isso, foram propositalmente lançadas aos estudantes questões referentes a essa tensão, as quais os convocaram a um posicionamento, a falarem de si e de seus sentimentos. Já nos primeiros diálogos o sentimento de vergonha surge nas discussões. Andressa, estudante do Setor de Ciências Jurídicas, em sua entrevista, continuou dando pistas para pensar sobre essa questão.

Pesquisador: Tu acha que existe algum sentido negativo em ser bolsista? Sei lá, que as pessoas possam ter vergonha disso.

E-Andressa: Ah, eu... não acontece comigo, mas eu acho que talvez aconteça, sim. Com quem depende de tudo, igual eu te disse. Depende da moradia, depende da universidade, depende da alimentação e ainda mais desse... talvez sim. Não sei, né? Talvez quem pense como benefício. Talvez quem não considere como um direito, principalmente. E, por ser... por obedecer um critério socioeconômico, né? Você se expõe ao dizer "eu sou bolsista.". Ou seja, "eu tenho baixa renda.". Não sei.

Ser um "dependente" é um primeiro elemento apresentado pela estudante como possibilidade para o sentimento de vergonha. Depender de tantas ações (e quanto mais, pior!) constitui um lugar não confortável, ao mesmo passo que receber algo como benefício, e não como direito, configura sentidos negativos, constrange. A recusa a esse lugar, que também foi manifestada em outras entrevistas, surge a partir da possibilidade de interpretação dos auxílios como "direito", uma contrapalavra a "benefício".

A questão feita pelo pesquisador no trecho acima, foi também apresentada em todos os diálogos individuais ou grupais com os estudantes. Assim, foi debatida no
Grupo focal 1, do qual participou Benício, estudante do Setor de Ciências Humanas:

G1-Benício: Então, eu não tenho medo de mostrar a minha... "ah, mas você é durão?"; "Eu sou, velho!". Pode ir lá na PROGRAD, pergunta pros caras lá, se eu passei na parada é porque eu sou durão, né? Sabe? "Ah, mas então você está bem, né? Não está pagando o restaurante.". Não, eu estou mal, né, velho? (risos) Estou mal, né, velho? Se eu estivesse bem eu estaria pagando! (risos)

No contexto dos diálogos do grupo, "durão" não está ligado a ideais de valente ou batalhador, mas sim de "duro", sem dinheiro. Trata-se de uso da palavra para referir à sua situação econômica. Em sua resposta, o estudante faz uma espécie de dramatização de um diálogo. Para essa voz, Benício é um estudante com fragilidade econômica, para ele, um durão. A ironia de Benício ao responder a essa voz dá pistas de que, do mesmo modo que Andressa, ele também produz uma ruptura. A oposição entre as palavras frágil e duro, no nível da polissemia, dá indícios de uma negação do estudante de um lugar caracterizado pela fragilidade. No diálogo que dramatiza, produz pela ironia a desconstrução do sentindo de que o beneficiado estaria numa condição boa ou confortável frente aos demais. Benício ri dessa possibilidade e reafirma: não está bem.

Se os lugares são tensos, entre o ocultar e o revelar, entre o estar bem e o estar mal, receber a bolsa é um direito ou um benefício? Os lugares-sentidos que essa discussão envolve, traz à tona questões referentes ao mérito e retrata a configuração das relações de alteridade, a serem capturadas no dialogismo interno da fala dos estudantes e entre eles. Nos trechos que seguem, essas tensões vêm à tona nos diálogos do Grupo 1, composto por Laura, Benício, Gustavo (estudantes de cursos do Setor de Ciências Humanas) e Silvia (do Setor de Ciências Biológicas). A questão do pesquisador teve como intenção explorar um terreno tenso.

Pesquisador: A ideia da bolsa é que seja uma política, assim como a cota é uma política, mas a bolsa é pra manter o aluno dentro da universidade. Como vocês veem essa questão? É um direito, é um benefício, como vocês se entendem nesse meio?

G1-Laura: Deveria ser um direito, mas ela ainda não é vista como um direito. Eu acho que ainda não. Por mais que já tenha algum tempo que as bolsas permanência são disponibilizadas, parece que elas ainda são muito relacionadas com a assistência pro aluno, um assistencialismo. 
G1-Gustavo: Assistência em qual sentido?

G1-Laura: Assistencialismo. Do tipo, assim: "vamos ajudar ele porque ele não tem condições.". Mas não assim... de se oficializar isso como um direito daquele aluno. Há uma diferença, querendo ou não. Tanto é que se isso fosse realmente instituído e visto como um direito dos alunos que têm essa necessidade, acabaria não ocorrendo o preconceito que você disse, que muitos falavam que "ah, não quero pedir porque...", porque tem vergonha, né? Que alguém saiba que "putz, aquele ali é um quebrado", né? Já está na universidade pública e ainda precisa de dinheiro porque não consegue se manter, né?

G1-Benício: É. É engraçado, eu fiquei encucado, né? Até na nossa cabeça, né? Com relação à benefício, né? Porque, na sociedade, a ideia é que você trabalha e vive, né? Muitas pessoas que eu conheço, se você falar que está numa pública que você não paga pra estudar, os caras já "Como assim? Existe uma?". Sabe? A falta de informação com relação a isso. "Você não paga?", falei "não.". "Mas como?", falei "Não, é pública, né?". Todo mundo paga, né? "Todos esses descontos que tem na, que vocês pagam trabalhando, revertem pra alguns setores". Impostos, né? E aí você vai falar que você ganha, mano? (ri) O cara fala "peraí!" Porque o estudar, ele ainda tem aquele pejorativo. "Você estuda?", né, velho? Como se não fosse...

G1-Gustavo: Parece coisa de vagabundo, assim, né? "Meu deus do céu, você ganha pra fazer o que?", né?

G1-Laura: "Nossa! Já tem mais de vinte anos e ainda é estudante!". (risos)

G1-Gustavo: Tipo coisa de vagabundo. (ri)

G1-Benício: É. Será que sou vagabundo, né, meu? Na hora você não analisa. Vamos fazer uma genealogia das palavras, que seria o trabalho? o trabalho seria você produzir. Você utilizar do seu conhecimento, tentar ler, né? Surgir alguma coisa nova, sei lá eu, crescimento, desenvolvimento. Trabalho, pra mim está ligado a isso, e não a fazer coisas repetitivas que dão dinheiro, pra te sustentar no final do... sabe? É diferente, é bem diferente. Muita gente coloca como se fosse uma coisa só, mas é diferente, né? Tanto é que nos últimos seis anos que eu estou aqui na universidade, o crescimento que eu tive, assim, é incomparável com os outros conhecimentos do tempo que eu fiquei... não que não teve, né? Eu adquiri uma experiência, que eu trabalhava e tal, mas hoje talvez seja...

G1-Gustavo: Mas é diferente, né? É mais intelectual, assim.
G1-Benício: Sim, e você é crítico, né cara? E pensar no que está fazendo, não fazer pra ganhar dinheiro. Mais do que ganhar dinheiro, é viver, né? Então, isso aí é um choque "como assim? Vou ganhar dinheiro?". Até tinha uma época que eu ficava meio assim, né? Porque "e aí, será que eu pego essa bolsa?".

G1-Laura: Culpado, né?

G1-Benício: Você fica aqui nesse ambiente... é, meio culpa. "Será que é pra mim?". Aí eu falei "poxa, meu, nesse ambiente, todo mundo... poxa, dos durão eu sou o campeão, né velho? É pra mim mesmo a parada! (ri) Sabe? Não tem que ficar com essa de... não, velho! É pra mim, é direito, cara. Eu que nunca tive um benefício, que nunca pude usufruir de... né, meu? Bem dessa. Que até, acho que não só as pessoas veem como uma ideia de benefício, assim, porque a Laura falou "é direito ou benefício?". Mas as vezes até a gente fica meio assim, né? "E aí, dentro dessa sociedade, será que é justo ou não é?". Poxa, é mais do que justo, né, cara?

As duas vozes presentes na fala de Benício retratam a indignação pela falta de informação do outro e a necessidade de se justificar para si e para esse outro, no interior de seu discurso, do porque não paga para estudar. As vozes retratam ainda o preconceito que o habita, o que se evidencia no "peraí", e pelo tom pejorativo da pergunta "você estuda?". Os sentidos da bolsa para o Grupo 1 conferem aos estudantes lugares-sentidos de quebrados, duros; o debate os incita à dúvida, reflexão e posicionamento sobre "direito e justiça". Assim, a discussão que busca transformar o sentido de trabalho - trabalho repetitivo, trabalho manual para trabalho intelectual - Ihes possibilita tornarem-se não apenas produtivos, mas críticos. Nesse meio, estudar é também "viver", experienciar, "é ser crítico", é, portanto, seu "direito". Por outro lado, o sentimento de culpa por "só estudar" ainda se mantém.

No Grupo 2, a mesma temática foi introduzida pelo pesquisador. Do G2 participaram Karen e Rafael, ambos de cursos do Setor de Ciências Humanas.

Pesquisador: E como é que vocês pensam a bolsa, vocês entendem como um direito dos alunos ou um benefício?

G2-Karen: (rindo) Um pouco dos dois. Ah, sei lá, um direito porque, tipo, nossos pais pagam impostos o tempo todo, assim, e a universidade deveria ser bem melhor, na verdade. A gente sabe que... é só ver essas coisas de política que a gente começa a lembrar, tem muita coisa do contra, principalmente na educação. Então, em parte é um direito, assim, 
que a pessoa... né, ela entrou na universidade pra.. nossa, pra quem veio de vida bem simples, assim, entrar na universidade é... meu deus do céu, é a glória. Ainda você conseguir receber por isso... mas tipo... é um direito mas... porque ela está trabalhando por isso, assim, entendeu? Ela não está só recebendo a bolsa. Teoricamente trabalha também. E um benefício porque... ah, sei lá. Não sei, acho que é isso.

G2-Rafael: É, meus pais vivem reclamando "que é um absurdo, que tinha que ganhar a bolsa só pelo direito,? de não ter condições,? e não ter que fazer nada.", assim.

G2-Karen: Ai, só que, daí, a pessoa meio que engessa. Ó, desculpe os teus pais também, mas se eles ficam pensando "ah, a gente é pobre, a gente tem que ser beneficiado de qualquer jeito, sem nada.", mas a pessoa tem que... né? Meu, vamos trabalhar então, vamos, né? Tipo, não "ah, eu vou receber porque eu sou pobre.". Aí a pessoa quer continuar pobre só pra receber. Ah, isso me lembrou aquele negócio lá, que tem uma mulher do nordeste lá que, só pra continuar recebendo uma bolsa lá, que ela ganha por filho... como é o nome da bolsa?

A imagem do ócio, negada pelos estudantes, leva à discussão do mérito em receber a bolsa. O acesso desses estudantes ao ensino superior federal (pessoas com baixa renda, que estudaram em escolas públicas e com histórias de vida que lhes deu muitos motivos para não acreditar ser possível chegar a uma instituição como essa), já não seria uma "glória", como diz Karen? Além do ingresso por cotas, receber uma bolsa para estudar não se constituiria uma situação de desigualdade? Conforme resolução descrita anteriormente, ao receber a bolsa permanência o estudante desempenhava 12 horas semanais de atividades formativas. Há uma atividade reconhecidamente produtiva que justifica o recebimento da bolsa - atividade que atende ao chamado da fala de Karen "Meu, vamos trabalhar então, vamos, né?". As atividades formativas emergem como possibilidade de caracterizar o auxílio como um direito, e o estudante como sujeito de direitos, não como beneficiado ou assistido - "é um direito, mas... porque ela está trabalhando por isso". Rafael contrapõe sua colega e afirma, pela voz de seus pais, a reivindicação da bolsa como direito, desvinculado da necessidade de uma contrapartida. Em resposta, Karen sustenta sua fala a partir da imagem do pobre "engessado" - o assistido, "conformado", que vai "continuar assim enquanto puder". Um incentivo do Estado a uma cidadania pior, errada. Essa mesma imagem é, ao mesmo tempo, reafirmada e refutada por Karen. Não quer o lugar-sentido de conformada, engessada, de que se contenta em receber algo pelo que não contribui. Receber para não fazer nada não é uma possibilidade aceitável para ela -"Não dá pra receber a bolsa sem fazer nada".

Para Benício, essa questão o deixa "encucado". Em meio ao impasse da definição da bolsa com um desses dois nomes, implicando também imagens e lugares possíveis a esses estudantes, a produtividade e o trabalho também são trazidos nos diálogos do primeiro grupo. Emerge desse diálogo a impossibilidade de o estudo ser compreendido como o que justificaria o mérito exigido. A voz social que significa o estudo como atividade improdutiva, trazida nas dramatizações de diálogos dos estudantes do primeiro grupo, não são apenas pronunciadas por pessoas outras (imaginárias ou reais), com as quais os estudantes dramatizam diálogos, mas compõem os enunciados dos próprios estudantes subjetivam-se nelas. Em outras palavras, o ficar encucado evidencia que o sentido do estudo como atividade não produtiva também é um sentido vivenciado e enunciado pelos próprios estudantes. A contradição de valores os constitui como sujeitos, não sendo algo externo a eles as dimensões social e econômica são condição material de suas formas de pensar, de ser e agir no mundo. Ao mesmo tempo em que se contrapõem ao pensamento de que estudo não é atividade produtiva, acabam por manter a mesma concepção da necessidade de algo que prove seus méritos pelo recebimento do auxílio. A lógica do mérito é mantida na busca pela desconstrução de lugares e sentidos que Ihes são atribuídos. Ter uma formação gratuita em uma universidade pública e ainda receber para estudar leva os estudantes a dialogar com vozes e sentidos socialmente construídos que os leva a se questionarem: Vagabundo? É justo? Essas questões que apresentam, seja em dramatizações em suas falas, seja em questionamentos que fazem a si mesmos e que os deixa encucados, os remetem cotidianamente a lugares e imagens, sentidos, que se constroem nas relações alteritárias, nas teias ideológicas que atravessam e fazem parte da instituição.

Fazer nada é motivador do sentimento de vergonha, o que mobiliza ao trabalho, assim, seu direito é garantido. $O$ mérito em receber a bolsa está na contrapartida (atividade formativa, conforme resolução UFPR, trabalho, nas falas dos estudantes), é a forma de não engessar, no sentido de ter mobilidade social; o mérito é pelo desempenho da atividade/trabalho, não 
pelo estudo. A bolsa opera produtivamente para todos. Porém, opera de modo diferenciado para os estudantes, a quem é posta de modo compulsório uma atividade a mais, além do estudo, na instituição e para si como forma de retificar a imagem de "vagabundos" ou ociosos, absolvendo-os da culpa. Assim, ao mesmo tempo em que os inclui, os exclui - a mais do que o estudo exigido os diferencia objetiva e subjetivamente. Prática que ao mesmo tempo opera como gestão de uma PP e como gestão e controle da alteridade.

\section{Lugares-Sentidos e Relações Alteritárias}

A contraposição de sentidos de direito e benefício é objetivada nos enunciados dos estudantes, refletindo e explicitando a tensão presente na arena de vozes sociais quanto a esse tema. Essa oposição foi propositalmente apresentada dessa forma pelo pesquisador a fim de produzir um profícuo debate sobre as relações cotidianas e seus efeitos para os estudantes, demandando destes um posicionamento frente a essa tensão. Posicionamento, na ótica do Círculo de Bakhtin, é posicionamento ético, síntese dialética entre subjetividade e objetividade (Pan et al., 2011). Assim, o sentido da bolsa é (trans)formado no diálogo que tecem os estudantes com as diversas vozes sociais a que respondem; inserem-se e fazem parte do debate, dão a ele seus tons emotivos-volitivos, o que implica os modos como (re)constroem sentidos sobre a bolsa e sobre si mesmos.

Por ser direcionada ao estudante "quebrado", "sem condições", ao pobre que historicamente tem sua imagem vinculada a uma falha individual ou cultural, como discutem Diniz (2007), Monnerat (et al., 2007) e Silva (2010), as discussões sobre a bolsa produzem dois efeitos aqui identificados: o reacender da compreensão da pobreza associada ao ócio (vinculação que produz aos estudantes sentimento traduzido como vergonha); e o "rotulamento" (identificado por Laura) enfrentado cotidianamente, negado ou ignorado pelos estudantes, a denunciar a ruína das relações de alteridade (Pan, 2003).

Nesse mesmo posicionamento frente aos questionamentos postos a eles e frente aos questionamentos que os próprios estudantes se puseram a debater (sejam com os envolvidos na situação concreta ou com vozes de pessoas reais ou vozes sociais, enquanto complexos sócio-ideológicos), foi possível perceber que, a partir dos sentidos que eram negociados nesses diálogos, os estudantes puderam (re)pensar seus posicionamentos frente aos sentidos que circulam e atravessam a universidade e que constituem seus cotidianos. Puderam, a partir daí, negociar outros modos de pensar e agir frente ao que têm experienciado - outros lugares.

Os sentimentos e as ações dos estudantes nos levam a pensar a complexidade do processo de inclusão/exclusão como definido por Sawaia ( 2006) e retratado nesta pesquisa. A dupla contrapartida da bolsa, 12 horas semanais de atividades formativas (ou "trabalho", nas palavras dos estudantes) e estudar (comprovação de rendimento), constituem-se, no caso da instituição estudada, um diferencial que, ao mesmo tempo, inclui e protege por meio das políticas diferenciadas de assistência e permanência, mas também mantém em situação de desigualdade, pela forma de gestão da alteridade, configuração e fixação da identidade. Os resguarda dos lugares-sentidos de ser pobre e ocioso, vagabundo, engessado, redimindo-os do sentimento de vergonha imputado pela culpa, uma vez que assumido como posição individual - e em segredo! Trata-se de uma solução individual, pensada nos moldes do individualismo contemporâneo como discutido por Gentili (1995), Palangana (2002), Yasbek (2003), Mancebo (2004), Maia e Mancebo (2010).

\section{Considerações finais}

Prática instituída dialogicamente como um desdobramento do PNAES, a bolsa retrata a opção ideológica da instituição e do Estado, sendo o sentimento de vergonha quem denuncia o como esse desdobramento produz a gestão da alteridade e a fixação de identidades; a contrapartida, assim, figura como prática social que marca a diferença dos bolsistas para com outros estudantes, uma diferenciação por sua condição de classe - "fragilidade socioeconômica".

O grupo focal, a partir da perspectiva do dialogismo bakhtiniano, possibilitou, ao dar voz aos estudantes, conhecer/possibilitar a expressão de sua experiência e sentimentos, de debater os sentidos da bolsa e de possibilitar posicionamentos e enfrentamentos na arena de vozes sociais. Compartilhar os sentidos da bolsa e os sentimentos que geram revelou o potencial produtivo da estratégia de posicionamento ético-político, tratando coletivamente a questão, sem individualiza-la, silenciá-la, em nome da proteção, permitindo assim o reconhecimento de um direito. $O$ potencial dessa estratégia evidencia também a contradição (não exclusiva) de uma política inclusiva pelo sofrimento ético-político dos estudantes, categoria usada por Sawaia (2006), que denuncia, pela emoção, a posição dos excluídos no processo da inclusão. A tonalidade ética da vivência cotidiana da 
desigualdade social, a afetividade e as emoções expressas pelos participantes da pesquisa possibilitou - a eles próprios e aos outros - (re)conhecer e (trans)formar os sentidos que os dão às suas experiências, bem como ressignificar seus atos (a si e aos outros) na arena social.

A contribuição aqui buscada foi a de problematizar as políticas na universidade, principalmente no que diz respeito a seus efeitos para os cotidianos dos estudantes, sobre a arena social em que constituem suas identidades profissionais; vozes sociais com as quais dialogam, se contrapõem, (re)afirmam, (trans)formam. Enquanto seres-evento abertos, existências em constante produção, os estudantes transitam, negociam, refutam, ironizam, afirmam, negam e reconstroem sentidos. Refazem cenas enunciativas possíveis, refazem as possibilidades de acabamento produzido nas relações alteritárias. Discutir a compreensão da bolsa como direito ou benefício não é buscar conhecer opiniões. Trata-se de produzir espaços em que sejam possíveis novos sentidos e lugares enunciativos, promovendo a consciência e o posicionamento dos estudantes, bem como sua avaliação participativa e efetiva da política da qual são alvo. Esses novos sentidos, negações, afrontas e ironias que foram assinaladas, mostram as tensões constitutivas das relações humanas que se perpetuam por relações de força entre grupos sociais e que (re)produzem-se não apenas nos momentos aqui exemplificados, mas no tempo grande da história. As PPs precisam, pois, de análises radicais de suas concepções, de modo que as populações alvo sejam concebidas, reconhecidas e sintam-se capazes de atuar politicamente. Desse modo, a discussão que aqui apresentamos continuará a ecoar em outros espaços e tempos, no constante diálogo de vozes sociais. Dada a escassez de produção de pesquisas nessa área, bem como sua relevância, espera-se, com este estudo, ter instigado o debate para que outras pesquisas possam ser fomentadas, para que o debate seja ampliado.

\section{Referências}

Amorim, M. (2002). Vozes e silêncio no texto de pesquisa em Ciências Humanas. Cadernos de Pesquisa, (116), 7-19. doi: 10.1590/S010015742002000200001

Amorim, M. (2004). O pesquisador e seu outro: Bakhtin nas Ciências Humanas. São Paulo: Musa Editora.

Aragaki, S. S., Lima, M. L. C., Pereira, C. C. Q., \& Nascimento, V. L. V. (2014). Entrevistas: negociando sentidos e coproduzindo versões de realidade. In M. J. P. Spink; J. I. M. Brigagão; V. L. V. Nascimento; \& M. P. Cordeiro (Orgs.), A produção da informação na pesquisa social: compartilhando ferramentas (pp. 57-72). Rio de Janeiro: Centro Edelstein de Pesquisas Sociais.
Bakhtin, M. (1997). Estetica da criação verbal. São Paulo: Martins Fontes

Bakhtin, M. (2010). Para uma filosofia do ato responsável. São Carlos: Pedro \& João Editores.

Bakhtin, M., \& Volochínov, V. N. (1990). Marxismo e Filosofia da Linguagem - Problemas fundamentais do método sociológico na Ciência da Linguagem. São Paulo: HUCITEC.

Bardagi, M.P., \& Hutz, C.S. (2009). "Não havia outra saída": percepções de alunos evadidos sobre o abandono do curso superior. Psico-USF, 14(1), 95-105. doi:. 10.1590/S1413-82712009000100010

Decreto n. 7.234 (2010, 19 de julho). Dispõe sobre o Programa Nacional de Assistência Estudantil - PNAES. Brasília: Diário Oficial da União.

Diniz, S. (2007). Critérios de justiça e programas de renda mínina. Revista Katálysis, 10(1), 105-114. doi: 10.1590/S1414-49802007000100012

Faraco, C. A. (2003). Linguagem e diálogo: as idéias linguísticas do círculo de Bakhtin. Curitiba: Criar Edições.

Flick, U. (2009). Introdução à pesquisa qualitativa ( $2^{\mathrm{a}}$ ed.). Porto Alegre: Artmed.

Fórum Nacional de Pró-Reitores de Assuntos Comunitários e Estudantis - FONAPRACE. (2001). Proposta para um Plano Nacional de Assistência aos Estudantes de Graduação das Instituições Públicas de Ensino Superior. Recuperado de http://www.unb.br/ administracao/decanatos/dac/fonaprace/documentos/pna.htm

Freitas, M. T. A. (2002). A abordagem sócio-histórica como orientadora da pesquisa qualitativa. Cadernos de Pesquisa, 116, 21-39. doi: 10.1590/S0100-15742002000200002

Freitas, M. T. A. (2009). A pesquisa de abordagem histórico-cultural: um espaço educativo de construção de sujeitos. Teias, 10(19), 1-12. Recuperado de http://www.e-publicacoes.uerj.br/index.php/ revistateias/article/view/24057

Frey, K. (2000). Políticas públicas: um debate conceitual e reflexões referentes à prática da análise de políticas públicas no Brasil. Planejamento e Políticas Públicas, 21, 211-259. Recuperado de http://www.en.ipea.gov.br/ppp/index.php/PPP/article/view/89

Garrido, E. N. (2015). A experiência da moradia estudantil universitária: impactos sobre seus Moradores. Psicologia: Ciência e Profissão, 35(3), 726-739. doi: 10.1590/1982-3703001142014

Gentili, P. (1995). Adeus à escola publica: a desordem neoliberal, a violência do mercado e o destino da educação das minorias. In P. Gentili (Org.), Pedagogia da exclusão: crítica ao neoliberalismo em educação (pp. 228-252). São Paulo: Vozes.

Geraldi, J. W. (2010). Ancoragens - estudos bakhtinianos. São Carlos: Pedro \& João Editores.

Instituto Nacional de Estudos e Pesquisas Educacionais Anísio Teixeira (2015). Censo da Educação Superior 2013: resumo técnico. Brasília: Autor. Recuperado de Disponível em: <http://download.inep.gov.br/ download/superior/censo/2010/resumo_tecnico_censo_educacao_ superior_2010.pdf>

Jobim e Souza, S., \& Albuquerque, E. D. P. (2012). A pesquisa em ciências humanas: uma leitura bakhtiniana. Bakhtiniana, 7(2), 109122. doi: 10.1590/S2176-45732012000200008

Jobim e Souza, S., \& Castro, L. R. (1998). Pesquisando com crianças subjetividade infantil, dialogismo e gênero discursivo. Psicologia Clínica, 9(1), 83-116.

Machado, J. P., \& Pan, M. A. G. S. (2012). Do nada ao tudo: políticas públicas e a educação especial brasileira. Educação \& Realidade, 37(1), 273-294. Recuperado de http://seer.ufrgs.br/ educacaoerealidade/article/view/16130 
Machado, J. P., \& Pan, M. A. G. S. (2013). Assistência estudantil: sentidos em (trans)formação. In N. L. Ferrarini \& D. Ruppel (Orgs.), Inclusão racial e social: considerações sobre a trajetória da UFPR (pp. 261288). Curitiba: UFPR.

Machado, J. P., \& Pan, M. A. G. S. (2014). Política pública e subjetividade: a assistência estudantil na universidade. Textos \& Contextos, 13(1), 184-198. doi: 10.15448/1677-9509.2014.1.15929

Maia, A. A. R. M., \& Mancebo, D. (2010). Juventude, trabalho e projetos de vida: ninguém pode ficar parado. Psicologia: Ciência e Profissão, 30(2), 376-389. doi: 10.1590/S1414-98932010000200012

Mancebo, D. (2004). Indivíduo e psicologia: gênese e desenvolvimentos atuais. In D. Mancebo \& A. M. Jacó-Vilela (Orgs.), Psicologia Social: abordagens sócio-históricas e desafios contemporâneos (pp. 35-48). Rio de Janeiro: EdUERJ.

Martins, R. D. O. (2001). Indivíduo e sociedade no discurso da política de ensino superior. Sociologias, (6), 94-120. doi: 10.1590/S151745222001000200006

Minayo, M.C.S.(2004). O desafio do conhecimento:pesquisa qualitativa em saúde. São Paulo: HUCITEC.

Monnerat, G. L., Senna, M. D. C.M., Schottz, V., Magalhães, R., \& Burlandy, L. (2007). Do direito incondicional à condicionalidade do direito: as contrapartidas do Programa Bolsa Família. Ciência \& Saúde Coletiva, 12(6), 1453-1462. doi:10.1590/S1413-81232007000600008

Moraes, R. C. (2002). Reformas neoliberais e políticas públicas: hegemonia ideológica e redefinição das relações Estado-sociedade. Educação \& Sociedade, 23(80), 13-24. doi: 10.1590/S0101-73302002008000002

Pacheco, E., \& Ristoff, D. I. (2004). Educação superior: democratizando o acesso. Brasilia: Instituto Nacional de Estudos e Pesquisas Educacionais Anísio Teixeira.

Palangana, I. C. (2002). Individualidade: afirmação e negação da sociedade capitalista. São Paulo: Sumus.

Pan, M. A. G. S. (2003). Infância, discurso e subjetividade: uma discussão interdisciplinar para uma nova compreensão dos problemas escolares (Tese de doutorado). Universidade Federal do Paraná, Curitiba. Recuperado de http://hdl.handle.net/1884/6022
Pan, M. A. G. S., Rossler, J. H., Ferrarini, N. L., Valore, L. A., \& Oliveira, S. N. (2011). Subjetividade: um diálogo interdisciplinar. Interação em Psicologia, 15(n. esp.), 1-13. doi: 10.5380/psi.v15i0.25365

Resolução N. ${ }^{\circ}$ 31/09 - COPLAD (2009, 29 de junlho) Regulamenta o Programa de Benefícios Econômicos para Manutenção aos estudantes de graduação e ensino profissionalizante da UFPR Curitiba: Conselho de Planejamento e Administração daUFPR.

Sawaia, B. B. (2006). As artimanhas da exclusão: análise psicossocial e ética da desigualdade social. Petrópolis - RJ: Vozes.

Severino, A. J. (2008). O ensino superior brasileiro: novas configurações e velhos desafios. Educar Em Revista, (31), 73-89. doi:10.1590/ S0104-40602008000100006

Silva, M. O. S. (2010). Pobreza, desigualdade e políticas públicas: caracterizando e problematizando a realidade brasileira. Revista Gaúcha de Enfermagem, 13(2), 155-163. doi:10.1590/S141449802010000200002

Sobral, A. U. (2005). Ato/atividade e evento. In B. Brait (Org.), Bakhtin: conceitos-chave (pp. 11-36). São Paulo: Contexto.

Spink, P., Ribeiro, M. A.T., Conejo, S. P., \& Souza, E. (2014). Documentos de domínio público e a produção de informações. In M. J. P. Spink, J. I. M. Brigagão, V. L. Nascimento, \& M. P. Cordeiro (Orgs.), A produção de informação na pesquisa social: compartilhando ferramentas (pp. 207-228). Rio de Janeiro: Centro Edelstein.

Sposito, M. P. (2008). Trajetórias na constituição de políticas públicas de juventude no Brasil. In M. V. Freitas \& F. Papa (Orgs.), Políticas Públicas: juventude em pauta (pp. 57-74). São Paulo: Cortez Editora.

Telles, V. S. (1998). Direitos sociais: afinal, do que se trata? Revista da USP, 37, 43-45. Recuperado de http://www.revistas.usp.br/revusp/ article/view/27023/28797

Vargas, M. L. F. (2011). Ensino superior, assistência estudantil e mercado de trabalho: um estudo com egressos da UFMG. Avaliação: Revista da Avaliação da Educação Superior, 16(1), 149-163. doi:10.1590/ S1414-40772011000100008

Yasbek, M. (2003). Fome Zero: uma política social em questão. Saúde e Sociedade, 12(1), 43-50. doi:10.1590/S0104-12902003000100007

\footnotetext{
${ }^{1}$ As instituições Privadas de Ensino Superior também foi alvo de ações como as que ocorreram no Ensino Público. Foi implantado o Programa Universidade para Todos (PROUNI) que fomentou a ampliação tanto no número de instituições quanto no de estudantes matriculados, como é possível observar pelos dados da tabela 1.9, do relatório do INEP (2015, p. 127).

${ }^{2}$ Criado em 12 de dezembro de 2007, pela Portaria Normativa nํ 39. Posteriormente a Portaria foi substituída pelo Decreto no 7.234 , em 19 de julho de 2010 , sem alterações no texto.

${ }^{3}$ Compreendidos a partir da concepção bakhtiniana de voz social - posicionamento realizado ética e esteticamente via linguagem, que se concretiza em diversificados signos e modos de comunicação, sempre numa relação dialógica.

${ }^{4}$ Transformação feita pela Portaria no 02/08 do Conselho Universitário, de 13/03/2008.
} 
Jardel Pelissari Machado, Mestre em Psicologia pela Universidade Federal do Paraná (UFPR - bolsista CAPES), é Doutorando em Psicologia no Programa de Pós-Graduação em Psicologia na Universidade Federal de Santa Catarina (UFSC) e Psicólogo da Universidade Federal do Paraná (UFPR). Endereço para correspondência: Rua Dr. Faivre, 405 - Ed. Dom Pedro II, 1ํo andar. CEP: 80060-140 Centro - Curitiba-PR. E-mail: machado.jardel@yahoo.com.br

Miriam Aparecida Graciano de Souza Pan, Doutora em Letras pela Universidade Federal do Paraná (UFPR) e Pós-doutora em Gestão da Educação Superior pela University of Texas at Austin (UT-Austin), é Professora Associada do Programa de Pós-Graduação em Psicologia e do Programa de Pós-graduação em Educação da Universidade Federal do Paraná (UFPR).

E-mail: miriamagspan@yahoo.com.br

Recebido em 25.Mai.16

Revisado em 04.Out.16

Aceito em 16.Dez.16 